\title{
GRUPOS ESCOLARES E ESCOLAS RURAIS NA PARAÍBA ESTADONOVISTA (1937-1945)
}

\begin{abstract}
Antonio Carlos Ferreira Pinheiro ${ }^{1}$ Evelyanne Nathaly Cavalcanti de Araújo Silva² Luiz Mário Dantas Burity ${ }^{3}$

RESUMO

O presente trabalho é resultante do desenvolvimento do projeto de pesquisa intitulado: "Escolarização para a moral, o civismo e o nacionalismo: os grupos escolares e as escolas rurais, espaços para a difusão dos ideais estadonovistas na Paraíba (1937-1945)”. Tem como principal fonte as notícias sobre educação publicadas no Jornal A União. Analisamos o material coletado tomando como referência alguns pressupostos teóricos propugnados por Antonio Gramsci $(1995 ; 2013)$ e por Eric Hobsbawm (1998). Tem como objetivo compreender as principais ações político-institucionais destinadas à organização do ensino primário na Paraíba. Articuladamente travamos uma discussão acerca das novas relações de poder estabelecidas durante o Estado Novo, a partir das interventorias de Argemiro de Figueiredo e de Ruy Carneiro, considerando a educação formal como parte significativa da organização do Estado e da vida daqueles que frequentaram a escola na cidade e no campo.

Palavras- chave: Grupo escolar; Escola rural; Estado Novo.
\end{abstract}

\section{SCHOOL GROUPS AND AGRICULTURAL SCHOOLS IN PARAÍBA "ESTADONOVISTA" (1937-1945)}

\begin{abstract}
The present work is resultant of the development of the intitled project of research: "Escolarização for the moral, the patriotism and the nationalism: the pertaining to school groups and the agricultural schools, spaces for the diffusion of the estadonovistas ideals in the Paraíba (1937-1945)". It has as main source the notice on education published in the periodical the Union. We analyze the collected material taking as reference some estimated theoreticians advocated for Antonio Gramsci $(1995$; 2013) e for Eric Hobsbawm (1998). It has as objective to understand the main politician-institucional actions destined to the organization of primary education in the Paraíba. Articuladamente we stop a quarrel concerning the new relations of being able established during the New State, from the interventorias of Argemiro de Figueiredo and Ruy Carneiro, considering the formal education as significant part of the organization of the State and the life of that they frequentaram the school in the city and the field.
\end{abstract}

Keywords: School group; Agricultural School; New State.

\section{Introdução}

Este trabalho é fruto das reflexões que vimos desenvolvendo no âmbito do Grupo de Estudos e Pesquisas História da Educação da Paraíba - HISTEDBR-PB, acerca do projeto intitulado: "Escolarização para a moral, o civismo e o nacionalismo: os grupos escolares e as escolas rurais, espaços para a difusão dos ideais estadonovistas na Paraíba (19371945)", vinculado a um projeto nacional de pesquisa denominado: "História da escola primária no Brasil: investigação em perspectiva comparada em âmbito nacional (1930 1961)". 4 
No transcurso da pesquisa foram catalogadas as notícias sobre educação, publicadas no Jornal A União, periódico oficial do Estado, nos números compreendidos pelo recorte temporal. O referido Jornal encontra-se no Arquivo Público Waldemar Bispo Duarte, situado na Fundação Espaço Cultural - FUNESC.

Analisamos o material coletado tomando como referência alguns pressupostos teóricos propugnados por Gramsci $(1995 ; 2013)$ no que concerne as reflexões acerca de como os espaços escolares podem ajudar na organização da cultura, considerando, ainda, o movimento conjuntural ocorrido no período aqui em estudo. Articuladas a esses pressupostos, trabalhamos também na perspectiva das categorias históricas: mudanças e permanências, fundamentais para a compreensão do sentido do passado, ou melhor, tentando apreender o significado sociocultural que tiveram os grupos escolares e as escolas rurais a partir da implementação político institucional do Estado Novo. Todas as mudanças ocorridas no Brasil naquele período estiveram condicionadas a um momento em que o capitalismo europeu começou a adentrar em uma profunda crise que terminou por gerar a Segunda Grande Guerra. Tal conflito fez mudar as relações entre as nações americanas com o "velho mundo" e ao mesmo tempo produziu mudanças internas, como foi o caso específico do Brasil que abraçou um regime político autoritário, centralizador e nacionalista. Nesse sentido, pensamos a instituição escolar como um espaço tomado por ambivalências, ou melhor, onde, de acordo com Hobsbawm (1998), ocorrem mudanças que se travestem de tradição e permanências que soam como inovação para determinados grupos sociais.

Como estamos trabalhando com dois tipos de instituições escolares consideramos também necessário destacar que

[...] além de ser criada pelo homem, a instituição apresenta-se como uma estrutura material que é constituída para atender a determinada necessidade humana, mas não qualquer necessidade. Trata-se de necessidade de caráter permanente. Por isso a instituição é criada para permanecer. (SAVIANI, 2007, p. 4).

Postos os referenciais norteadores de nossa discussão, este estudo tem como objetivo compreender a organização do ensino primário na Paraíba, principalmente considerando o processo de expansão de dois tipos de instituição escolar, a saber, o grupo escolar e a escola rural, essa pesquisa adentrou as discussões travadas pela historiografia acerca das relações de poder na sociedade paraibana entre os anos 1937-1945 e do papel que teve a educação formal na organização do Estado e da vida daqueles que frequentaram a escola na cidade e no campo.

O surgimento e expansão desses dois tipos de instituições escolares são marcados por conjunturas políticas, sociais e econômicas e porque não também ideológicas muito distintas. Os grupos escolares, primeiramente, instalados nos maiores centros urbanos de cada unidade da federação, nos primeiros anos da Primeira República, foram idealizados como um significativo elemento da modernização escolar brasileira, tomados pela racionalização e higienização geográfica, social e cultural. Enquanto isso o campo, ainda ligado à forma de organização social patriarcal dos latifúndios, permaneceu quase que intocado pelo Estado até o advento da ditadura getulista.

Com o golpe de 1937 o homem de São Borja ${ }^{5}$ afastou importantes líderes políticos e grupos da elite latifundiária e comerciária para a oposição. Restava saber, no entanto, como legitimar o regime de exceção que acabara de instaurar e com isso manter-se no controle do Estado brasileiro por mais alguns anos. Mas, Getúlio Vargas não demorou a agir, já na 
constituição outorgada naquele mesmo ano concedeu alguns direitos aos trabalhadores que levaram ao fortalecimento do trabalhismo ${ }^{6}$ brasileiro, cujo ápice foi a Consolidação das Leis do Trabalho - CLT, em 1943.

Paralelamente ao fortalecimento de sua imagem entre os trabalhadores urbanos o dito "Pai dos Pobres" também planejou uma política de legitimação do Estado brasileiro no meio rural. Através da ação de um grupo de intelectuais foi pensada a Escola Rural, a partir da qual além das primeiras letras seria direcionado o ensino profissional agrícola e a educação moral, com forte teor nacionalista, às populações do campo. Assim, além de confrontar o poder dos grandes latifundiários, Getúlio e seus aliados políticos também fortaleceram e centralizaram o poder do Estado em suas mãos.

Dois interventores federais governaram a Paraíba durante o Estado Novo, quais sejam: Argemiro de Figueiredo (1937-1940) ${ }^{7}$ e Ruy Carneiro (1940-1945). Em continuidade à postura administrativa que iniciara em 1934, Argemiro de Figueiredo manteve uma boa relação com a elite agrária paraibana, foi responsável também pelo processo de modernização das cidades de João Pessoa e Campina Grande assim como criou grupos escolares em todo o Estado. Em 1940, no entanto, devido aos conflitos interoligárquicos e à necessidade de haver um maior controle por meio do Interventor sobre o Estado paraibano, Ruy Carneiro foi nomeado para este cargo, dando início a uma administração tomada pela contenção de gastos, assistencialismo e pela expansão de escolas rurais ${ }^{8}$.

\section{Um segundo momento do processo de expansão dos grupos escolares na Paraíba ${ }^{9}$ : escolarização para o citadino}

O Estado Novo se caracterizou como um período histórico marcado por uma forte presença do patriotismo, da civilidade e do discurso nacionalista. Durante aquele regime de exceção esses e outros elementos fizeram parte dos projetos do Estado para a sociedade dita brasileira ${ }^{10}$, estando presente no cotidiano da população e mais ainda no cotidiano escolar. Dessa forma a educação foi uma das instâncias que o governo estadonovista utilizou para inserir na sociedade sua concepção doutrinária de caráter autoritário. (ROCHA, 2000). Nessa perspectiva mais ampla Horta (1994) ainda aponta em sua obra que para o Ministro Capanema

a educação não pode adotar uma atitude de neutralidade, [...] não pode limitar-se, de modo céptico ou indeciso, simplesmente a preparar o homem para a ação [...]. Assim 'a educação não pode ser neutra no mundo moderno'. E também no Brasil, já começado 'pelas tempestades do tempo presente', a educação não podia ser neutra, mas teria que 'se colocar decisivamente a serviço da Nação’. (CAPANEMA, 1942 apud HORTA, 1994, p. 166).

Nesse sentido, o ensino primário, principalmente aquele desenvolvido no âmbito dos grupos escolares, teve um papel fundamental para introduzir o ensino patriótico, nacionalista e cívico no cotidiano escolar citadino. Especial atenção, no entanto, foi dada ao ensino primário realizado nas regiões sul e sudeste em virtude da grande concentração de migrantes europeus de origem alemã, italiana, lituana, polonesa e também asiática, com destaque para a japonesa. (SCHWARTZMAN,1983). 
No caso da região nordeste, esse aspecto foi pouco relevante, considerando que apesar de ter ocorrido fluxos migratórios italianos, espanhóis e também japoneses ${ }^{11}$, esses foram em menores números. Nesse sentido, a discussão sobre a necessidade de nacionalizar o ensino tomou outra dimensão, qual seja: o de tentar diminuir ou pelo menos neutralizar as especificidades regionais, uma vez que o que estava em pauta era o ideário de uma identidade nacional, que deveria ser construída forçadamente pela via do Estado autoritário. Outro aspecto refere-se a uma maior centralização e controle sobre esse nível de ensino. Sobre isso, Schwartzman (1983, p. 360) destacou e que "a partir de 1942, o Governo Federal iniciou uma nova política com relação ao ensino primário", ou seja, "cumpria-lhe, por um lado, forçar o aumento das dotações estaduais e municipais destinadas ao ensino primário; e por outro lado, encaminhar aos Estados auxílio financeiro federal". Entre os diversos problemas identificados pelos estadonovistas, um foi retomado com grande ênfase, isto é, a necessidade de superar ou pelo menos minimizar o grande número de analfabetos adultos. Para tanto, o Governo Federal iniciou um movimento de educação popular, se preocupando desta forma também com a educação primária supletiva. (SCHWARTZMAN, 1983).

Todavia, para viabilizar a investida contra esse grande mal, entre tantos outros, era necessário implementar uma grande reforma educacional que deveria se iniciar nos estados, contudo articuladamente com as grandes diretrizes propugnadas pelo poder central. Na verdade, em novembro de 1938, pelo decreto-lei $\mathrm{n}^{\circ} 868$, foi criada a Comissão Nacional de Ensino Primário (CNEP). (ROCHA, 2000). A função desta Comissão foi a de realizar uma modificação na política que regia o ensino primário, no qual cabia aos estados e municípios compartilhar essa responsabilidade com o poder federal e estabeleceria todas as grandes diretrizes destinadas a esse nível de ensino. Assim sendo, a ideia de Vargas era a de federalizar a organização da educação como um todo.

$\mathrm{Na}$ administração do Interventor Argemiro de Figueiredo foram construídos vários prédios escolares no Estado. É possível perceber como nesse momento a criação dos grupos escolares esteve vinculada à construção de seus edifícios, conforme já analisado por Pinheiro (2002). De acordo com o Decreto $n^{\circ} 795$, de $1^{\circ}$ de abril de 1937:

Art. $1^{\circ}$ - Ficam creados os seguintes Grupos Escolares: "Gentil Lins", em Sapé; "Dr. José Maria”, em Pilar; "Dr. Appolonio Zenayde", em Piancó; "Professor Luiz Aprigio", em Mamanguape; "Professor Clementino Procopio", em Campina Grande e "Dr. José Leite", em Conceição, todos de 2. " categoria; "Monsenhor Salles", em Galante e "Dr. José Tavares", em Queimadas, ao municipio de Campina Grande, de 3. a categoria. [...]. (PARAÍBA, Estado da. Jornal A União, 02.04.1937, p. 4, aspas no original).

Mediante as notícias publicadas no Jornal A União foi possível perceber que já no ano de 1937 estavam próximas da conclusão as obras de dois grupos escolares no interior do Estado, um na cidade de Conceição, denominado Grupo Escolar José Leite e outro em Misericórdia, denominado de Grupo Escolar D. Vital. (PARAÍBA, Estado da. Jornal A União, 20.01.1937, p. 1). Ainda segundo o mesmo periódico, nessa data ocorreu o término das obras de melhoramento do Grupo Escolar Epitácio Pessoa, localizado na capital do Estado. (PARAÍBA, Estado da. Jornal A União, 30.01.1937, p. 3). No município de Sapé, o Grupo Escolar Gentil Lins, foi inaugurado e recebeu a visita do então Interventor Argemiro de Figueiredo. 
No ano de 1938 estavam em construção os grupos escolares de Picuí, Santa Rita, Taperóa, Cabaceiras e Serraria ${ }^{12}$ e a inauguração do Grupo Escolar Celso Cirne, na cidade de Moreno. A construção e inauguração de grupos escolares obedeceram, não raras vezes, aos moldes estabelecidos pela Diretoria de Viação e Obras Públicas. (PARAÍBA, Estado da. Jornal A União, 25.01.1939, p. 1-2).

Para se ter noção mais precisa acerca da expansão dessas instituições podemos apontar que no ano de 1934, por exemplo, haviam no estado da Paraíba 34 grupos escolares e, em 1939, esse número já havia se elevado para 42, tendo o governo de Argemiro de Figueiredo construído 17 grupos escolares. Associado à criação e construção de novos grupos escolares muitos já existentes também passaram por beneficiamentos tais como reformas, melhoramentos e adaptações, entre eles destacam-se os seguintes: Grupo Escolar Santo Antonio e o Grupo Escolar Dr. Tomaz Mindêlo, ambos localizados na capital, além do Grupo Escolar de Araruna, Grupo Escolar de Antenor Navarro, Grupo Escolar de Patos, Grupo Escolar de Santa Luzia, Grupo Escolar Solon de Lucena, situado na cidade de Campina Grande, Grupo Escolar de Cajazeiras, Grupo Escolar de Areia, Grupo Escolar de Bananeiras e o Grupo Escolar de Itabaiana. (PARAÍBA, Estado da. Jornal A União, 25.01.1939). Naquele mesmo ano, isto é, em 1939 foi publicado o

Decreto ${ }^{\circ} 1.274$, de 26 de janeiro de 1939 a Secretaria da Viação e Obras Públicas [que] abriu um crédito especial de 200:000\$000 (duzentos contos de réis), destinado às despesas com melhoramentos e a construção de grupos escolares, auxílios e outros serviços. (PARAÍBA, Estado da. Jornal A União, 27.01.1939, p. 4).

As inovações socioeducacionais que se projetaram nos governos do período estadonovista na Paraíba tiveram a preocupação com a reestruturação dos padrões e das formas de gerenciamento dos estabelecimentos públicos de ensino. Assim sendo, foram implementadas, em anexo aos grupos escolares ou fora deles, as instituições auxiliares do ensino, que se configuraram a partir da participação ativa daqueles que frequentavam e faziam parte do corpo docente dos grupos escolares. Nessa perspectiva, a seguir passaremos a analisar como essas instituições auxiliares do ensino contribuíram para o processo de consolidação da educação pública na Paraíba.

Em 25 de janeiro de 1939 foi publicada no Jornal A União uma extensa matéria intitulada Movimento educacional e cultural na Paraíba no Govêrno Argemiro de Figueirêdo. Nela foram explicitadas as preocupações do referido Interventor acerca das necessárias renovações educacionais que deveriam ser implementadas a partir da criação das instituições auxiliares do ensino. Vale ressaltar que até então já existiam em funcionamento, em alguns poucos grupos escolares, as caixas, as bibliotecas e as cooperativas escolares, entretanto, elas não tinham ainda assumido um caráter de política de governo. Tal mudança começou a ocorrer partir de 1939, quando as instituições auxiliares do ensino passaram a ser visualizadas como práticas pedagógicas renovadoras que além de ajudarem no processo de ensino-aprendizagem também auxiliariam no sentido da formação do homem citadino enquadrado nos ideais estadonovistas.

Em 1940, umas das instituições auxiliares do ensino que mais teve expressividade foram às cooperativas escolares, anexas aos grupos escolares, que em sua grande maioria serviram para trabalhar junto às crianças o espírito de brasilidade pautado no sentimento patriótico. Para tanto, logo no início daquele ano letivo, os diretores de grupos escolares foram convocados para uma audiência pelo Departamento de Assistência ao Cooperativismo. (PARAÍBA, Estado da. Jornal A União, 24.01.1940). Tal reunião 
objetivou orientar os referidos dirigentes escolares a implementarem as cooperativas escolares: nesse sentido, "fundar cooperativas escolares é a palavra de ordem dentro das nossas modernas normas de ensino". (PARAÍBA, Estado da. Jornal A União, 06.11.1940, p. 3). No ano seguinte, já durante a administração Ruy Carneiro, foi a vez da implementação, de forma mais abrangente, das caixas e das bibliotecas escolares, além dos clubes agrícolas.

Porém, foi a partir do ano de 1942 até o último ano do Estado Novo, que ocorreu uma mudança no panorama das implementações das instituições auxiliares do ensino na Paraíba, uma vez foram publicadas várias Leis Orgânicas para a educação, que terminaram por ampliar enormemente a quantidade e os tipos de instituições auxiliares, conforme podemos observar no quadro que se segue:

\section{QUADRO I}

Tipos de Instituições Auxiliares de Ensino implementadas no ano de 1942, por grupo escolar e por cidade

\begin{tabular}{|c|c|c|}
\hline Nome & CIDADE & INSTITUIÇÃO AUXILIAR DO ENSINO \\
\hline $\begin{array}{l}\text { Grupo Escolar Francisco } \\
\text { Duarte }\end{array}$ & Serraria & $\begin{array}{l}\text { - Caixa Escolar Antonio Bento } \\
\text { - Grêmio Cívico Literário Borja Peregrino } \\
\text { - Clube Agrícola Alberto Torres } \\
\text { - Círculo de Pais e Mestres } \\
\text { - Jornal infantil } \\
\text { - Teatro infantil }\end{array}$ \\
\hline Grupo Escolar João Úrsulo & Santa Rita & $\begin{array}{l}\text { - Biblioteca Infantil Ecila Lins } \\
\text { - Grêmio Infantil Primeiro de Janeiro } \\
\text { - Liga de Assiduidade } \\
\text { - Grêmio Escolar } 21 \text { de abril } \\
\text { - Liga da Bondade } \\
\text { - Grêmio Infantil Três de Maio } \\
\text { - Clube dos Amigos da Natureza } \\
\text { - Grêmio Infantil } 5 \text { de Agosto } \\
\text { - Clube de Leitura e Audição } \\
\text { - Grêmio Escolar } 7 \text { de Setembro } \\
\text { - Clube de Linguagem } \\
\text { - Grêmio Escolar } 13 \text { de Maio } \\
\text { - Bandeira de Saúde }\end{array}$ \\
\hline $\begin{array}{l}\text { Grupo Escolar Duarte da } \\
\text { Silveira }\end{array}$ & João Pessoa & $\begin{array}{l}\text { - Caixa Escolar Abel da Silva } \\
\text { - Cooperativa Duarte da Silveira } \\
\text { - Círculo de Pais e Mestres } \\
\text { - Biblioteca Pedagógica }\end{array}$ \\
\hline $\begin{array}{l}\text { Grupo Escolar Álvaro } \\
\text { Machado }\end{array}$ & Areia & $\begin{array}{l}\text { - Caixa Escolar Simão Patrício } \\
\text { - Círculo das Mães Alice Monteiro } \\
\text { - Grêmio Literário e Artístico José Rodrigues de } \\
\text { Aquino } \\
\text { - Biblioteca Infantil } \\
\text { - Clube Agrícola Antenor Navarro } \\
\text { - Jornal infantil Primavera } \\
\text { - Clube de Leitura }\end{array}$ \\
\hline $\begin{array}{l}\text { Grupo Escolar Antenor } \\
\text { Navarro }\end{array}$ & Guarabira & - Liga de Bondade Darcí Vargas \\
\hline Grupo Escolar Irineu Jófili & Esperança & $\begin{array}{l}\text { - Liga da Bondade } \\
\text { - Círculo de pais e mestres }\end{array}$ \\
\hline Grupo Escolar Rio Branco & Patos & - Clube Infantil Lítero-recreativo \\
\hline Grupo Escolar D. Vital & Itaporanga & $\begin{array}{l}\text { - Círculo de Pais e Mestres } \\
\text { - Jornal Infantil }\end{array}$ \\
\hline
\end{tabular}




\begin{tabular}{|c|c|c|}
\hline & & $\begin{array}{l}\text { - Cooperativa Escolar } \\
\text { - Biblioteca dos Professores } \\
\end{array}$ \\
\hline Grupo Escolar Alcides Bezerra & Cabaceiras & $\begin{array}{l}\text { - Círculo de Pais e Mestres } \\
\text { - Liga da Bondade } \\
\text { - Biblioteca General José Pessoa }\end{array}$ \\
\hline Grupo Escolar Padre Ibiapina & Itabaiana & $\begin{array}{l}\text { - Clube Agrícola Alberto Torres. } \\
\text { - Museu escolar (proposta do Inspetor Pedro Jorge de } \\
\text { Carvalho, a ser organizado) }\end{array}$ \\
\hline Grupo Escolar Félix Daltro & Taperoá & $\begin{array}{l}\text { - Centro de Cultura Lourenço Filho. } \\
\text { - Clube de Leitura Rui Barbosa. } \\
\text { - Grêmio Infantil } \\
\text { - Pelotão da Saúde } \\
\text { - Caixa Escolar } \\
\text { - Cooperativa Escolar } \\
\text { - Clube de Linguagem Antenor Navarro } \\
\text { - Clube Agrícola }\end{array}$ \\
\hline Grupo Escolar de Pilar & Pilar & $\begin{array}{l}\text { - Clube Agrícola Anísio Borges } \\
\text { - Clube Agrícola Pimentel Gomes } \\
\text { - Pelotão da Saúde }\end{array}$ \\
\hline $\begin{array}{l}\text { Grupo Escolar Peregrino de } \\
\text { Carvalho }\end{array}$ & Espírito Santo & $\begin{array}{l}\text { - Museu Escolar } \\
\text { - Círculo de Pais e Mestres }\end{array}$ \\
\hline Grupo Escolar Afonso Campos & Pocinhos & $\begin{array}{l}\text { - Clube Agrícola } \\
\text { - Círculo de Pais e Mestres } \\
\text { - Biblioteca Infantil Padre Antonio Galdino } \\
\end{array}$ \\
\hline Grupo Escolar Gentil Lins & Sapé & $\begin{array}{l}\text { - Clube Agrícola João Pessoa } \\
\text { - Biblioteca Francisca de Farias Caldas }\end{array}$ \\
\hline Grupo Escolar de Laranjeiras & Laranjeiras & $\begin{array}{l}\text { - Círculo de Pais e Mestres } \\
\text { - Jornal Infantil } \\
\text { - Clube de Leitura } \\
\text { - Estava previsto também a organização de um Clube } \\
\text { Agrícola }\end{array}$ \\
\hline Grupo Escolar Gama e Mélo & $\begin{array}{l}\text { Princesa } \\
\text { Isabel }\end{array}$ & $\begin{array}{l}\text { - Liga da Bondade } \\
\text { - Clube de Linguagem } \\
\text { - Círculo de Pais e Mestres }\end{array}$ \\
\hline Grupo Escolar Luiz Aprígio & Mamanguape & $\begin{array}{l}\text { - Por iniciativa do inspetor Fenelon Camara, foi } \\
\text { organizado um Círculo de Pais e Mestres } \\
\text { - Biblioteca Pedagógica Umbelina Garcês }\end{array}$ \\
\hline Grupo Escolar de Piancó & Piancó & $\begin{array}{l}\text { - Biblioteca pedagógica para professores. } \\
\text { - Clube Agrícola. } \\
\text { - Círculo de pais e mestres }\end{array}$ \\
\hline Grupo Escolar Xavier Junior & Bananeiras & $\begin{array}{l}\text { - Jornal infantil O Saber } \\
\text { - Círculo de Pais e Mestres Prof. Leônidas Santiago } \\
\text { - Reorganização do Clube Agrícola José Augusto da } \\
\text { Trindade }\end{array}$ \\
\hline $\begin{array}{l}\text { Grupo Escolar de Catolé do } \\
\text { Rocha }\end{array}$ & $\begin{array}{l}\text { Catolé do } \\
\text { Rocha }\end{array}$ & $\begin{array}{l}\text { - Dois Clubes de linguagem. } \\
\text { - Biblioteca pedagógica Ruy Barbosa }\end{array}$ \\
\hline $\begin{array}{lll}\text { Grupo } & \text { Escolar } & \text { Monsenhor } \\
\text { Milanez } & & \\
\end{array}$ & Cajazeiras & - Clube de Leitura Rui Barbosa \\
\hline $\begin{array}{lll}\text { Grupo } & \text { Escolar } & \text { Apolônio } \\
\text { Zenaide } & & \\
\end{array}$ & $\begin{array}{l}\text { Alagôa } \\
\text { Grande }\end{array}$ & - Biblioteca pedagógica \\
\hline Grupo Escolar João da Mata & Pombal & $\begin{array}{l}\text { - Biblioteca Infantil João Vieira Carneiro } \\
\text { - Clube Agrícola Ruy Carneiro } \\
\text { - O Infante, jornal dos alunos }\end{array}$ \\
\hline Grupo Escolar Celso Cirne & $\begin{array}{l}\text { Vila } \\
\text { Moreno }\end{array}$ & $\begin{array}{l}\text { - Círculo de Pais e Mestres Nevinha Cavalcanti } \\
\text { - Caixa Escolar Professor Eduardo Medeiros } \\
\text { - Jornal infantil O Clarim } \\
\text { - Clube Agrícola } 13 \text { de Fevereiro } \\
\text { - Biblioteca Américo Falcão }\end{array}$ \\
\hline
\end{tabular}




\begin{tabular}{|c|c|c|}
\hline & & - Teatro infantil Silvino Lopes \\
\hline Grupo Escolar Joaquim Távora & $\begin{array}{l}\text { Antenor } \\
\text { Navarro }\end{array}$ & $\begin{array}{l}\text { - Clube Agrícola } \\
\text { - Biblioteca pedagógica }\end{array}$ \\
\hline $\begin{array}{lll}\text { Grupo } & \text { Escolar } & \text { Professor } \\
\text { Lordão } & & \\
\end{array}$ & Picuí & $\begin{array}{l}\text { - Círculo de Pais e Mestres Silvino Macêdo } \\
\text { - Biblioteca Dr. Saldanha } \\
\text { - Jornal O Juvenil } \\
\text { - Museu Escolar Luciano Jaques de Morais }\end{array}$ \\
\hline Grupo Escolar João Soares & Caiçára & $\begin{array}{l}\text { - Jornal Infantil O Cruzeiro } \\
\text { - Biblioteca pedagógica dos professores }\end{array}$ \\
\hline Grupo Escolar Batista Leite & Souza & $\begin{array}{l}\text { - Biblioteca Pedagógica Cônego Viana } \\
\text { - Liga de Enfermagem } \\
\text { - Liga da Bondade } \\
\text { - Clube Agrícola }\end{array}$ \\
\hline $\begin{array}{l}\text { Grupo Escolar do Município de } \\
\text { Bonito }\end{array}$ & Bonito & - Círculo de pais e mestres \\
\hline Grupo Escolar Targino Ribeiro & Araruna & $\begin{array}{l}\text { - Círculo de pais e mestres } \\
\text { - Biblioteca Pedagógica Professor } \\
\text { Amaro Gomes de Almeida } \\
\text { - Clube Agrícola Dr. Guedes Pereira }\end{array}$ \\
\hline Grupo Escolar Solon de Lucêna & $\begin{array}{l}\text { Campina } \\
\text { Grande }\end{array}$ & - Biblioteca de professores \\
\hline Grupo Escolar Coêlho Lisboa & Santa Luzia & - Círculo de pais e mestres \\
\hline $\begin{array}{l}\text { Grupo Escolar de São João do } \\
\text { Cariri }\end{array}$ & $\begin{array}{l}\text { São João do } \\
\text { Cariri }\end{array}$ & $\begin{array}{l}\text { - Clube de linguagem } \\
\text { - Clube Agrícola Pascoal Trócoli }\end{array}$ \\
\hline Grupo Escolar de Queimadas & Queimadas & - Clube Agrícola João Pessoa \\
\hline $\begin{array}{l}\text { Grupo Escolar Cel. Antonio } \\
\text { Pessoa }\end{array}$ & Umbuzeiro & $\begin{array}{l}\text { - Clube Agrícola Dr. Epitácio Pessoa Sobrinho } \\
\text { - Reorganização da biblioteca infantil Professora } \\
\text { Adamantina Tavares Barreto }\end{array}$ \\
\hline Grupo Escolar Prof. Cardoso & Alagoa Nova & - Cinzel, órgão oficial dos alunos. \\
\hline $\begin{array}{l}\text { Grupo Escolar Isabel Maria das } \\
\text { Neves }\end{array}$ & João Pessoa & $\begin{array}{l}\text { - Primeiras iniciativas favoráveis à criação do Teatro } \\
\text { Infantil da Paraíba }\end{array}$ \\
\hline $\begin{array}{l}\text { Grupo Escolar Miguel Santa } \\
\text { Cruz }\end{array}$ & Monteiro & - Pelotão de Saúde Osvaldo Cruz \\
\hline Grupo Escolar Epitácio Pessoa & João Pessoa & $\begin{array}{l}\text { - Em } 20 \text { de setembro de 1942, fundação do Núcleo de } \\
\text { Jovens Artistas - O teatro e a sua função educacional. }\end{array}$ \\
\hline
\end{tabular}

Fonte: Vários números do Jornal A União, 1942. PARAÍBA, Estado da. Jornal A União, 1942.

Os anos posteriores acabaram por dar prosseguimento ao que havia se iniciado em 1942. Todavia, algumas instituições auxiliares de ensino tiveram maiores expressividades enquanto outras nem tanto, mesmo que tenha continuado as suas atividades alimentadas por aqueles que fizeram parte do corpo administrativo e pedagógico dos grupos escolares.

O governo de Ruy Carneiro também apresentou dados significativos acerca do ensino na Paraíba, porém voltou-se, prioritariamente a elaboração da reforma do ensino, bem como com as renovações e modernizações pedagógicas para todo o Estado paraibano. Apesar da Lei Orgânica do ensino primário somente ter sido implementada no ano de 1946, ou seja, pós Estado Novo, foi pensada e articulada durante a vigência do referido período político ditatorial.

A partir da Reforma do Ensino no Estado da Paraíba, realizada no ano de 1942, várias medidas foram tomadas para reorganizar o ensino em geral. A Paraíba, por ter sido o primeiro estado a ter pedido orientação do Governo Federal para os problemas educacionais ${ }^{13}$ que vinham sendo apresentados para a efetivação dos projetos do Estado Novo, acabou por institucionalizar o discurso patriótico, nacional e cívico, em especial nos grupos escolares. O Interventor Ruy Carneiro, juntamente com o professor Lourenço Filho, 
tiveram participação importante para o encaminhamento do início da Reforma do Ensino na Paraíba.

Com a posse de Calheiros Bonfim no cargo de diretor, o Departamento de Educação passou a apresentar uma maior expressividade na organização institucional da educação paraibana, no sentido de que todos trabalhassem de acordo com a política nacional, ou seja, nada poderia acontecer nessa área sem que passasse pelo diretor do Departamento de Educação, desde os simples pedidos de licença para tratamento de saúde ou para resolver problemas pessoais até as solicitações de transferência de um estabelecimento de ensino para outro, substituições de professores, exonerações, contratos, criação de novas escolas (rurais, reunidas) e grupos escolares, entre outros. Dessa forma, o gabinete do Diretor do Departamento de Educação passou a ser um local onde eram resolvidas as mais variadas questões relacionadas à educação na Paraíba. Nesse sentido, Calheiro Bonfim, extremamente sintonizado com as diretrizes estabelecidas pelo governo central, passou a exercer um importante papel no processo de organização de um novo sistema educacional. Não foi à-toa que o professor Lourenço Filho, diretor do Instituto Nacional de Estudos Pedagógicos, em 1942, considerou que "o Govêrno da Paraíba deu um bélo exemplo de compreensão da integração nacional a ser realizada pela educação". (PARAÍBA, Estado da. Jornal A União, 03. 03. 1942, p. 3).

É sabido que o período varguista se propôs a reorganizar o país fundamentado nas concepções mais radicais do nacionalismo e que para isso era necessário envolver todas as instâncias da sociedade em prol dessa reorganização. A educação foi, neste conjunto panorâmico, um dos ramos que o presidente Getúlio Vargas se propôs a observar e reformar com minúcia, afinal de contas, a partir do ensino seria possível incutir na população estudantina os conceitos e formas de perceber o mundo de acordo como estava sendo pensado às estruturas superiores de poder. A iniciativa do Governo da Paraíba em solicitar apoio do Governo Federal para uma reforma no ensino do Estado foi algo de grande relevância. Tanto é que o ministro da educação Gustavo Capanema declarou em telegrama enviado ao interventor Ruy Carneiro, apoio ao plano de reforma do ensino na Paraíba. (PARAÍBA, Estado da. Jornal A União, 12.03.1942, p. 3).

A reforma do ensino primário foi um dos aspectos prioritários apontados pelos administradores públicos, visto que, o professor Lourenço Filho já se posicionava sobre a situação do ensino primário, afirmando que

[...] de cada cem alunos, de todas as idades, e em todas as escolas brasileiras, 90 cursam escolas primárias. De cada cem professores, 73 empregam a sua atividade nas escolas desse gráu. De cada cem contos, destinados aos serviços de ensino oficial, em geral, 74 são nelas consumidos. (PARAÍBA, Estado da. Jornal A União, 25.03.1942. p. $5)$.

A partir das matérias publicadas no Jornal A União, sobre o ensino primário, percebemos que durante o Estado Novo, não apenas no estado da Paraíba, mas no país como um todo, havia uma preocupação central com este grau de ensino. Essa questão foi considerada tão relevante que o tema geral do VIII Congresso Brasileiro de Educação foi sobre "a educação primária fundamental - objetivos e organizações - nas pequenas cidades e vilas do interior, na zona rural comum, nas zonas rurais de imigração e nas zonas do alto sertão". (PARAÍBA, Estado da. Jornal A União, 25.03.1942. p. 5).

Conforme já mencionado anteriormente o governo de Ruy Carneiro se deteve mais nas questões relacionadas à qualidade do ensino (incluindo as reformas) do que de sua 
expansão. Assim, dos 25 novos grupos escolares criados na Paraíba durante o Estado Novo apenas cinco ocorreram durante a sua administração. (Consultar anexo II em PINHEIRO, 2002). Nesse sentido, é possível observar que nos primeiros anos da década de 1940 o movimento de criação dessas instituições escolares arrefeceu. Em seus projetos para o ensino primário nas cidades a proposta desse Interventor pareceu estar mais preocupado com o "tipo" de ensino destinado, sobretudo, aos filhos das elites, que com a expansão desse modelo de instituição escolar.

\section{Escolas Rurais: civilizar e profissionalizar o "homem do campo" para atender os interesses da nação}

Após a proclamação da República uma nova postura intelectual era exigida da sociedade política brasileira: ideologicamente marcada por um maior racionalismo, essa nova organização significou uma mudança na forma com a qual a sociedade política se estruturava no poder público e na maneira de se pensar a Nação brasileira.

Com o cientificismo e o positivismo que ganharam força as cidades se tornaram o centro do desenvolvimento econômico em todo o país e a política educacional brasileira não procurou desenvolver a escolarização rural. Assim, "a sociedade brasileira somente despertou para a educação rural por ocasião do forte migratório interno dos anos 1910/20, quando um grande número de rurícolas deixou o campo em busca das áreas onde se iniciava um processo de industrialização mais amplo". (LEITE, 1999, p. 28).

Surgia enquanto política de Estado o "Ruralismo Pedagógico", que visava, sobretudo, uma maior integração do homem à economia agropastoril: "ocasionando, de certa forma, a valorização da visão fisiocrata, na qual a riqueza tem origem na produção agrícola e, também, a tendência de colocar o Brasil em um destino econômico agropecuário". (LEITE, 1999, p. 29). Porém, é necessário considerar que o "Ruralismo Pedagógico" foi aplicado, sobretudo, a um número restrito de instituições de ensino profissional. Na Paraíba são exemplos a Escola de Sericultura, a Escola Correcional Presidente João Pessoa e a Escola de Agronomia do Nordeste, além dos clubes agrícolas. Esses últimos eram espaços de ensino anexos às instituições escolares do meio urbano, pouco interferindo no fazer-se ${ }^{14}$ do homem do campo. De acordo com Pereira (2010, p. 50), é possível perceber que nessas instituições "se pretendia mudar o [...] ensino tão arraigadamente tradicional e livresco, incorporando um ensino mais prático, mais técnico e mais próximo da realidade local dos alunos".

No entanto, apenas com a publicação de um artigo do professor Sizenando Costa, em 1935, na Revista do Ensino ${ }^{15}$ da Paraíba, a proposta de escolarização rural a partir um modelo específico de instituição escolar passou a ser considerada pela sociedade política paraibana. Tratava-se de uma instituição de ensino primário localizada no meio rural, que deveria constar em seu currículo, principalmente, o ensino profissional agrícola. A arquitetura escolar, ou seja, o prédio escolar era muito simples e composta por uma sala de aula com a casa do professor em anexo. A organização escolar pedagógica era prioritariamente constituída por salas multisseriadas, ou melhor, por uma sala multisseriada. $^{16}$

Constatamos a partir da documentação consultada que tanto Argemiro de Figueiredo, quanto alguns de seus assessores mais próximos, dentre os quais José Baptista de Mello ${ }^{17}$, Diretor Instrução Pública, recepcionaram positivamente as ideias de Sizenando Costa sobre a importância e necessidade de se expandir a escola e ensino rural na Paraíba.

De acordo com Pinheiro (2002) após a leitura do artigo do professor Sizenando Costa o então interventor prometeu a criação, ainda em 1935, de uma instituição naqueles moldes 
em Barreiras, no município de Santa Rita. No entanto, não foram encontrados registros da criação dessa instituição, especialmente nas inúmeras edições do Jornal A União que foram consultados no transcorrer desta pesquisa. É interessante também ressaltarmos que nenhuma notícia foi vinculada no referido periódico sobre a criação de qualquer outra escola rural até 1938, quando finalmente foi publicado, no mês de maio, um decreto criando a Escola Rural Modelo ${ }^{18}$ na Capital do Estado. (PARAÍBA, Estado da. Jornal A União, 13.05.1938). De acordo com algumas informações colhidas, entre os anos de 1938 a 1941, é provável que a referida escola tenha funcionado em um prédio cedido pela Igreja Santa Júlia, localizada no bairro da Torrelândia, que nos primeiros anos do século XX era zona rural do município de João Pessoa, sob a denominação "Escola Rural n 1 " ou apenas "Escola n"1".

Ainda em 1938, temos a informação que "a próxima instalação da escola rural modelo" (PARAÍBA, Estado da. Jornal A União, 07.10.1938, p. 225) seria na Fazenda Simões Lopes ${ }^{19}$, em uma propriedade que fora recentemente doada pelo Governo Federal ao governo do estado da Paraíba. Todavia, em 1941, outras notícias publicadas no mesmo periódico, apontam para a criação futura de uma escola rural nessa mesma Fazenda, afirmando, contudo, que havia ocorrido um atraso no processo de transferência da posse de uma parte da referida propriedade. (PARAÍBA, Estado da. Jornal A União, 19.09.1941). ${ }^{20}$

No livro A Administração paraibana em 1941, elaborado a partir do relatório enviado pelo Interventor Ruy Carneiro ao presidente Getúlio Vargas e publicado pela Imprensa Oficial do Estado da Paraíba, no ano seguinte, ou seja, em 1942, encontramos a indicação das melhorias ocorridas no ensino primário com especial destaque para a ampliação de oferta de vagas no ensino rural. Segundo a referida publicação Ruy Carneiro afirmou que "em comemoração ao 'Dia da Juventude', baixei um decreto-lei em 19 de Abril do ano passado criando 40 novas escolas primárias no Estado, que foram imediatamente preenchidas e já se acham em funcionamento". (PARAÍBA, 1942, p. 66).

É necessário lembrar que o Dia da Juventude, em 1941, foi comemorado na data aniversária do presidente Getúlio Vargas em quase todos os estados da federação por sugestão de Ruy Carneiro. Por esse motivo essa festividade se tornou um momento fundamental para a afirmação deste como Interventor paraibano, tendo sido um evento amplamente difundido pela imprensa oficial do Estado, que aproximava a sua imagem à do presidente da República e demonstrava sua adesão ao projeto nacional estadonovista. Isso explica em parte a importância que a escola rural teve no seu projeto político. A perspectiva fundamental era a de levar os ideais nacionalistas e patrióticos para o "homem do campo".

Esse novo momento para o processo de criação de escolas rurais na Paraíba pode ser observado também nas notícias publicadas no Jornal A União a partir de 1941. Naquele ano uma quantidade significativa de artigos acerca do tema foram publicados pelos intelectuais paraibanos como América Monteiro, Guimarães Duque e Mário Gomes. Em meio à discussão promovida por esses atores sociais, verificamos os elogios que eram frequentemente destinados a proposta pedagógica do professor Sizenando Costa, que publicara um livro intitulado A Escola Rural (1941) detalhando às prescrições para o funcionamento desse tipo instituição escolar, mas, sobretudo, defendia-se bastante da necessidade de se estabelecer o ensino profissional agrícola para a formação dos jovens camponeses. Mas, ao mesmo tempo reconheciam as dificuldades encontradas pelos administradores públicos no processo de criação dessas escolas. Nas palavras de Mário Gomes no artigo Descentralização do Professorado (PARAÍBA, Estado da. Jornal A União, 13.05.1941, p. 3), o problema da não efetivação da Escola Rural na Paraíba até aquele ano era responsabilidade dos professores, visto que havia uma 
[...] mania de todos os recém-diplomados se localizarem nas capitais e não de se dedicar exclusivamente á sociedade no que diz respeito ao aperfeiçoamento e progresso, causando assim um desequilíbrio nas forças educativas do Estado.

Nesse texto o autor corrobora com o discurso nacionalista que prevê o sacrifício dos interesses individuais pelos interesses coletivos, exigindo dos professores uma postura de abdicação de sua vida citadina pelo amor à profissão e compromisso com a Nação, e seguindo para o magistério no meio rural. No entanto, em um segundo artigo intitulado Rendimento Escolar, publicado cinco dias após o primeiro, o autor parece mudar completamente o seu ponto de vista, apontando que "as causas as vezes alheias á vontade do professor, influem para [que] a escola não dê o resultado desejado". (PARAÍBA, Estado da. Jornal A União, 17.05.1941, p. 3), enumerando as seguintes causas:

a) pobreza extrema da população escolar;

b) pouco interesse dos pais na educação dos filhos;

c) ocupações rurais da infância escolar no tempo da plantação e colheita;

d) má distribuição das escolas pelas zonas mais populosas, do interior;

e) influência política na orientação do ensino. (PARAÍBA, Estado da.

Jornal A União, 17.05.1941, p. 3).

Nesse artigo o professor e intelectual condenou, sobretudo, considerando o último item acima citado, a influência da ordem política paternalista como um empecilho para o desenvolvimento nacional e a melhoria da qualidade de vida dos "homens do campo" a partir de sua frequência nas escolas rurais. Dessa forma, a intransigência dos coronéis era a verdadeira fronteira estabelecida entre o poder do Estado e o latifúndio que resultavam na "extensão" ${ }^{21}$ das políticas públicas que eram mais evidenciadas na cidade do que no campo. Esse aspecto nos fornece fortes indícios acerca do imperativo que se apresentava aos administradores públicos (poder público e estatal) em adentrar no espaço rural. Nesse sentido, foi o ensino um dos meios pensados e utilizados para controlar os corpos e as mentes dos trabalhadores agrícolas, em um processo de adesão à proposta nacionalista e patriótica.

Em uma palestra realizada, em 1943, no Cassino da Lagoa ${ }^{22}$, Sizenando Costa leu um trabalho de sua autoria sobre "Escola Rural Modêlo", realizando uma apreciação sobre os métodos pedagógicos que deveriam ser adotados no ensino rural. Sugeriu, ainda, a criação de uma escola desse tipo na Fazenda Simões Lopes. (PARAÍBA, Estado da. Jornal A União, 3 out. 1943, p. 3). Assim sendo, o referido estudioso denunciou que a instituição ainda não havia sido inaugurada até aquele ano, mesmo tendo sido publicado em 1938 e 1941 a consecução de sua efetivação, conforme mencionamos anteriormente neste estudo. Todavia, naquele mesmo ano de 1943 foi publicada outra notícia afirmando que: "teremos então a Escola Rural Modêlo, a ser instalada nos terrenos da Fazenda Simões Lopes". (PARAÍBA, Estado da. Jornal A União, 20.02.1943, p. 5), ou seja, após cinco anos movidos pelas constantes propostas de sua criação, é que a Escola Rural Agrícola, localizada no Horto Simões Lopes, teve sua obra iniciada ${ }^{23}$. 


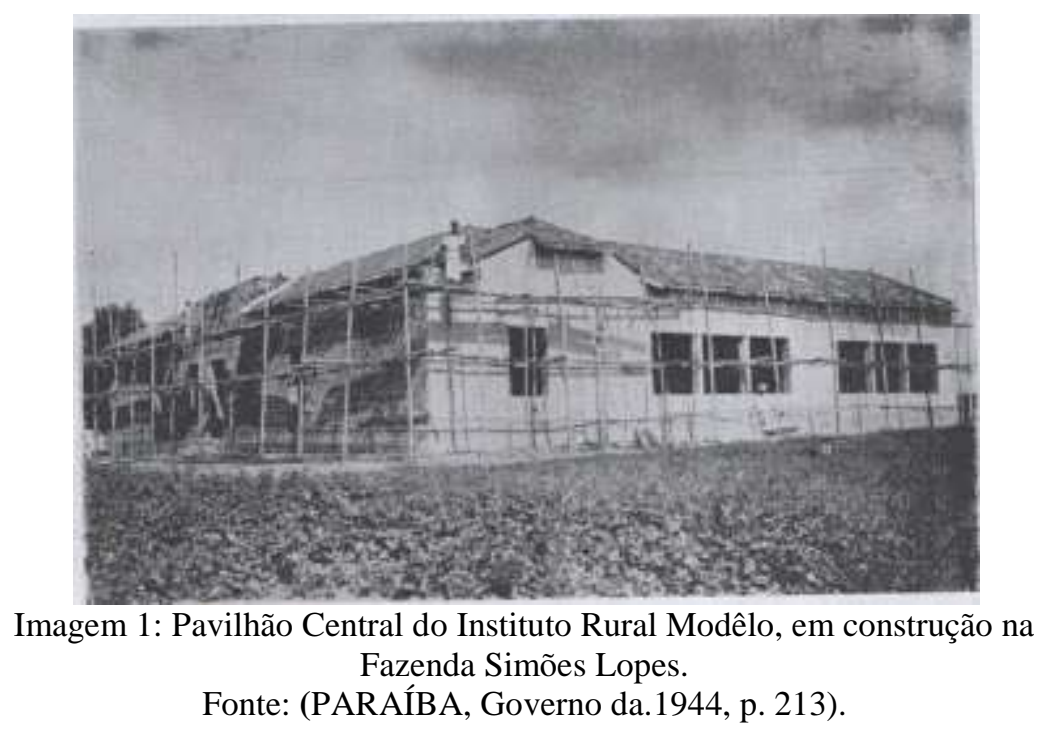

Na fotografia acima, publicada em 1944, podemos observar o adiantado da obra, uma vez que já estava sendo telhada. Sua estrutura, também, apresenta dimensões significativas se comparado ao modelo tradicional presente nas propostas de construção das escolas rurais. Tais características físicas até certo modo demonstram a importância dada pelas autoridades paraibanas acerca de uma escola destinada a atender as possíveis demandas emanadas do meio rural. A imagem corresponde ao prédio principal, e possuía "quatro salas de aula, cada uma com $48 \mathrm{~m}^{2}$, uma sala para o museu industrial; uma sala para a administração; gabinete médico e dentário, biblioteca, quatro gabinetes sanitários". (PARAÍBA, Governo da. 1944, p. 213).

A Fazenda Simões Lopes, por se localizar na Capital do Estado, marcou também uma mudança da relação da cidade de João Pessoa, com todo o interior paraibano, que esteve até a década de 1930 muito mais vinculado economicamente com à cidade e o porto de Recife. O que reafirma a constante tentativa do Estado da Paraíba para controlar a economia e a estrutura política do setor agropastoril paraibano.

É necessário destacar que antes mesmo da criação do Instituto Rural Modêlo a Fazenda Simões Lopes já era considerado um importante espaço de produção e difusão de tipos e tecnologias agrícolas, de forma que a implementação de uma escola representou mais um insumo no sentido de aprimorar o desenvolvimento científico destinado ao setor agropastoril, acompanhando assim outras experiências que foram implementadas em outras instituições tais como: a Escola de Agronomia do Nordeste, a Granja São Rafael e o Colégio Vidal de Negreiros, além da criação de outras menores escolas rurais que se empenharam em civilizar o homem do campo a partir do seu lugar de origem e atrelado à produção agrícola. Nesse sentido, conforme expressou Burity (2012), a ideia de civilizar estava acoplada ao sentido de preparar o homem para viver numa sociedade mais desenvolvida economicamente.

\section{Considerações Finais}

A escolarização primária na Paraíba estadonovista se deu a partir de uma intensa correlação de forças entre os governos federal, estadual e a sociedade civil, esta ainda em processo de organização e a criação dos grupos escolares e das escolas rurais responderam a diferentes demandas sociais, culturais e econômicas, ou melhor, foi sendo constituída em uma nova conjuntura política que exacerbou a ideia de construção de uma nação forte, 
autenticamente brasileira, nacionalista e patriótica. Todavia, nas duas interventorias, durante a vigência do Estado Novo, alguns aspectos foram se modificando ou equacionando-se aos interesses daqueles que estiveram mais próximo do poder. $\mathrm{Na}$ primeira, ou seja, na interventoria de Argemiro de Figueiredo ocorreu uma maior proximidade com os latifundiários paraibanos proporcionando, o que pode aparecer como contraditório, a expansão de grupos escolares que foram construídos em várias cidades do interior. Entretanto, se na sua administração demonstrou o encantamento pela proposta pedagógica de Sizenando Costa isso não implicou em efetivação prática, uma vez que não lhe interessava desarticular o poder patriarcal e paternalista dos latifundiários, ou seja, quanto menos presença do Estado nos latifúndios melhor para manter o seu poder mandonista.

Na segunda interventoria, ou melhor, na de Ruy Carneiro a construção de grupos escolares arrefeceu-se dando lugar a busca da melhoria da qualidade desse ensino e ao mesmo tempo esboçou-se uma política ainda fracamente delineada para o meio rural com as escolas rurais. Nesse sentido, mais próximo dos comerciantes citadinos, Ruy Carneiro procurou centralizar e fortalecer o poder do Estado nas suas mãos e diminuir a influencia dos coronéis do interior na gestão do Estado. Para isso utilizou vários mecanismos de exercício do poder entre eles a busca de adentrar nos latifúndios, ou seja, ampliar a presença do Estado com a criação de escolas rurais, disciplinando o "homem do campo", tornando-os civilizados e cidadãos prontos para atender os interesses da nação.

\section{Referências}

BURITY, Luiz Mário Dantas. As formações humanísticas e profissionais no Estado Novo: a experiência paraibana no Governo de Ruy Carneiro. In: XV Encontro Estadual de História - Paraíba - História e Sociedade: Saberes em diálogo. Cajazeiras, PB: Universitária - UFPB, 2012, paginação irregular.

CITTADINO, Monique; SILVA, Ana Beatriz Ribeiro Barros. Estado Novo na Paraíba: Aspectos iniciais da Interventoria de Ruy Carneiro. In: CITTADINO, Monique e GONÇAVES, Regina Célia. (Org.). Historiografia em diversidade: ensaios de história e ensino de história. Campina Grande, PB: Universitária - UFCG, 2008. p. 121-141.

COSTA, Sizenando. A Escola Rural. Rio de Janeiro, DF: Serviço Gráfico do IBGE, 1941. GOMES, Angela de Castro. A invenção do trabalhismo. $3^{\mathrm{a}}$ ed. Rio de Janeiro, RJ: FGV, 2005.

GOMES, Mário. Descentralização do Professorado. In: Jornal A União, João Pessoa, 13 de maio de 194, paginação irregular.

GOMES, Mário. Rendimento Escolar. In: Jornal A União, João Pessoa, 17 de maio de 194, paginação irregular.

GRAMSCI, Antonio. Os intelectuais e a organização da cultura. $9^{\mathrm{a}}$ ed. Tradução de Carlos Nelson Coutinho. Rio de Janeiro, RJ: Civilização Brasileira, 1995.

GRAMSCI, Antonio. Cadernos do Cárcere: Introdução ao estudo da filosofia; a filosofia de Benedetto Croce. Tradução de Carlos Nelson Coutinho. Vol. 1, Rio de Janeiro, RJ: Civilização Brasileira, 2013.

GURJÃO, Eliete de Queiróz. Morte e vida das oligarquias - Paraíba (1889-1945). João Pessoa, PB: Universitária- UFPB, 1994. 
HOBSBAWM, Eric. Sobre História. Tradução de Cid Knipel Moreira. São Paulo, SP: Companhia das Letras, 1998.

HORTA, José Silvério Baia. O hino, o sermão e a ordem do dia: regime autoritário e a educação no Brasil. Rio de Janeiro, RJ: Ed. UFRJ, 1994.

KYOTOKU, Virgínia Regis de Barros Correia. A imigração japonesa no Brasil: rastros na Paraíba (1938-1985). João Pessoa, PB: Fundação Francisco Mascarenhas -Faculdades Integradas de Patos (Especialização), 2009.

LEITE, Sérgio Celani. Escola Rural: urbanização e políticas educacionais. São Paulo, SP: Cortez, 1999.

MELLO, José Baptista. Evolução do ensino na Paraíba. 2a ed. João Pessoa, PB: Imprensa Oficial, 1956.

MELLO, José Octávio de Arruda. Os italianos na Paraíba - da capital ao interior. João Pessoa, PB: A União, 2006.

PARAÍBA, Governo da. Realizações do Governo Argemiro de Figueirêdo. João Pessoa, PB: Departamento de Estatística e Publicidade, 1938.

PARAÍBA, Governo da. A Administração paraibana em 1941. João Pessoa, PB: Imprensa Oficial, 1942.

PARAÍBA, Governo da. Serviços e Realizações em 1943. João Pessoa, PB: Imprensa Oficial, 1944.

PARAÍBA, Estado da. Jornal A União. João Pessoa, 20 de Janeiro de 1937.

. Jornal A União. João Pessoa, 30 de Janeiro de 1937.

Jornal A União. João Pessoa, 02 de Abril de 1937.

Jornal A União. João Pessoa, 13 de Maio de 1938.

Jornal A União. João Pessoa, 7 de Outubro de 1938.

. Jornal A União. João Pessoa, 25 de Janeiro de 1939.

. Jornal A União. João Pessoa, 27 de Janeiro de 1939.

. Jornal A União. João Pessoa, 24 de Janeiro de 1940.

Jornal A União. João Pessoa, 06 de Novembro de 1940.

. Jornal A União, João Pessoa, 6 de julho de 1941.

. Jornal A União, João Pessoa, 11 de julho de 1941.

Jornal A União, João Pessoa, 19 de setembro de 1941.

Jornal A União. João Pessoa, 03 de Março de 1942.

Jornal A União. João Pessoa, 12 de Março de 1942.

Jornal A União. João Pessoa, 25 de Março de 1942.

Jornal A União. João Pessoa, 20 de Fevereiro de 1943.

Jornal A União. João Pessoa, 3 de Outubro de 1943.

PARANHOS, Adalberto. O roubo da fala. $2^{\text {a }}$ ed. São Paulo, SP: Boitempo, 2007. 
PEREIRA, Priscilla Leandro. Experiências educacionais na Paraíba para o meio rural (1930-1937). Monografia (Graduação em Educação). Universidade Federal da Paraíba. João Pessoa: UFPB, 2010.

PINHEIRO, Antonio Carlos Ferreira. Da era das escolas isoladas à era dos grupos escolares na Paraíba. Campinas, SP: Autores Associados e Universidade de São Francisco, 2002.

. A era das escolas rurais primárias na Paraíba (1935 a 1960). In: SCOCUGLIA, Antonio Celso; MACHADO, Charliton José. (Orgs.). Pesquisa e historiografia da educação brasileira. Campinas, SP: Autores Associados, 2006, p.133-159.

PONZI, Alfio. Presença italiana na Paraíba. Rio de Janeiro, RJ: Achiamé, 1988.

ROCHA, Marlos Bessa Mendes da. Educação conformada: a política de educação no Brasil 1930-1945. Juiz de Fora, MG: Ed. UFJF, 2000.

SANTANA, Martha Maria Falcão de Carvalho e Moraes. Poder e Intervenção Estatal Paraíba: 1930-1940. João Pessoa, PB: Universitária UFPB, 2000.

SAVIANI, Demerval. Instituições escolares no Brasil: conceito e reconstrução histórica. In: NASCIMENTO, Maria Isabel Moura; SANDANO, Wilson; LOMBARDI, José Claudinei; SAVIANI, Demerval. (Orgs.). Instituições escolares no Brasil: conceito e reconstrução histórica. Campinas, SP: Autores Associados, 2007. p. 3 - 27.

SCHWARTZMAN, Simon. Estado Novo, um Auto-retrato. Brasília, DF: CPDOC/FGC e Universidade de Brasília, 1983.

SILVA, Jean Patrício da. Poder local e história política: a interventoria Ruy Carneiro no Estado da Paraíba (1940-1945). Monografia (Licenciatura em História). Universidade Federal da Paraíba, João Pessoa, 2009.

THOMPSON, Edward Palmer. A formação da classe operária inglesa. Tradução de Denise Bottman. Vol. 6 ${ }^{\text {a }}$ ed. São Paulo, SP: Paz e Terra, 2011.

\section{Notas}

\footnotetext{
${ }^{1}$ Doutor em História da Educação pela Universidade Estadual de Campinas (UNICAMP), professor do Programa de Pós-graduação em Educação da Universidade Federal da Paraíba (UFPB) E-mail: acfp@terra.com.br

${ }^{2}$ Graduada em História e em Pedagogia pela Universidade Federal da Paraíba (UFPB) e mestranda do Programa de Pós-graduação em Educação da mesma Universidade. E-mail: evelyanne@ hotmail.com.

${ }^{3}$ Graduando em História e bolsista do Programa de Iniciação Científica/CNPq da Universidade Federal da Paraíba (UFPB). E-mail: marioburity@ hotmail.com

${ }^{4}$ Projeto Integrado de Pesquisa apresentado ao CNPq - Edital Universal MCT/CNPq n ${ }^{\circ}$ 014/2010, Coordenado nacionalmente pela professora Dra. Rosa Fátima Souza. Participam do referido projeto 18 unidades da federação brasileira e conta com a participação de aproximadamente 40 renomados pesquisadores, além de alunos de mestrado, doutorado e de iniciação científica.

${ }^{5}$ Vocativo dado ao Getúlio Vargas.

${ }^{6}$ De acordo com Gomes (2005, p. 14) foi com o Estado Novo que o trabalhismo, "proposta de participação política que conceituava cidadania, democracia, política", se fortaleceu enquanto ação do Estado. Nas palavras de Paranhos (2007) esse foi o Estado que "roubou" a fala dos trabalhadores, que há muito já reivindicavam melhores condições de trabalho.

${ }^{7}$ Vale ressaltar que Argemiro de Figueiredo assumiu a interventoria na Paraíba em 1935, eleito pela Assembléia Legislativa e continuou no cargo após a implantação do Estado Novo. Para maiores informações consultar Gurjão (1994).
} 
${ }^{8}$ Conforme analise das informações contidas no livro de Santana (2000), o texto de Cittadino e Silva (2008), e o estudo monográfico de Silva (2009). Consultar também: Realizações do Governo Argemiro de Figueirêdo (1938),

${ }^{9}$ Segundo Pinheiro (2002) o primeiro momento do processo de expansão dos grupos escolares na Paraíba ocorreu de 1916, data de criação do seu primeiro grupo escolar e se estendeu até 1929.

${ }^{10}$ No referido recorte cronológico a questão da "identidade brasileira" ainda não estava bem resolvida, de forma que descrever sua população civil como brasileira significaria assumir o discurso unificador empenhado pelo Estado em diversos momentos da história do Brasil.

${ }^{11}$ No caso específico da Paraíba há dois estudos sobre a migração italiana, entretanto os seus autores Ponzi (1988) e Mello (2006) não se detiveram nas questões relacionadas com a escolarização. Aspecto semelhante ocorre em relação ao estudo realizado por Kyotoku (2009) sobre a migração japonesa na Paraíba.

${ }^{12}$ Cf. Decreto ${ }^{\circ} 1043$, de 13 de maio de 1938.

${ }^{13}$ Sobre a Reforma do Ensino na Paraíba, ver Jornal A União (03.03. 1942, p. 03).

${ }^{14} \mathrm{De}$ acordo com Thompson (2011) o ser humano constitui suas experiências a partir do seu fazer-se.

${ }^{15} \mathrm{O}$ acesso às informações presentes na referida revista foram acessadas a partir da análise realizada por Pinheiro (2006), visto que o volume no qual o artigo do professor Sizenando Costa foi publicado já não se encontra disponível no acervo documental do Instituto Histórico e Geográfico Paraibano, onde Pinheiro (2006) realizou a sua pesquisa.

${ }^{16} \mathrm{O}$ ensino multisseriado consiste no processo de escolarização de alunos em diferentes níveis de desenvolvimento escolar pelo mesmo professor e na mesma sala.

${ }^{17}$ Escreveu a importante obra Evolução do ensino na Paraíba, em 1936, no qual demonstrou entusiasmo pela Escola Rural. Para tanto, no referido livro chegou a descrever que desde o Império, Beaupeire Rohan que fora presidente da Província da Parahyba do Norte, propunha desde 1858, "um ensino que hoje constitui o grande desejo dos educadores modernos" e explica que em seus projetos de educação industrial haviam orientações que influenciaram os partidários da educação rural.

Embora tenha sido utilizada a edição de 1956 é possível perceber que José Baptista de Mello não alterou os capítulos do livro que se referem ao período anterior à administração de Argemiro de Figueiredo, apenas acrescentando os capítulos referentes aos anos subsequentes.

${ }^{18}$ Interessante observar o uso do termo "a Escola Rural Modelo" e não "uma Escola Rural Modelo", conforme documento consultado.

${ }^{19}$ De acordo Pinheiro (2002, p. 284) a Fazenda Simões Lopes se localizava no Alto Santa Rosa/ PB.

${ }^{20} \mathrm{Na}$ ocasião da publicação dessa notícia, os professores Sizenando Costa e Álvaro de Carvalho enviaram felicitações ao interventor Ruy Carneiro pela criação de tal instituição. Cf. Jornal A União, 6 jul. 1941, p. 5; Jornal A União, 11 jul. 1941, p. 1. Na segunda notícia, o professor Álvaro de Carvalho aparece como "Dr. Álvaro de Carvalho" e foi referenciado como "ilustre catedrático do Liceu Paraibano".

${ }^{21}$ É claro que essa extensão ficava apenas no nível do discurso. Na prática as políticas públicas para a melhoria da qualidade de vida do homem do campo foram mais lentas e com uma qualidade muito inferior às políticas direcionadas ao meio urbano.

${ }_{22}$ Tradicional restaurante localizado no centro da cidade de João Pessoa, onde se reuniam fequentemente intelectuais, administradores públicos e professores para realizarem palestras ou encontros políticos.

${ }^{23} \mathrm{~A}$ ausência de informações mais precisas acerca da criação dessa instituição, no Jornal A União, exigiu que outros tipos de documentos fossem acessados como foi o caso das mensagens que o interventor Ruy Carneiro enviou ao presidente Getúlio Vargas informando os resultados de sua administração nos anos de 1941, 1942 e 1943, e que contem um tipo de narrativa que destinava-se a um público leitor diferente do jornal, embora ambos sejam fontes oficiais. No que se refere à educação, por exemplo, os jornais sempre destacam os pensamentos dos intelectuais e autoridades acerca dos temas que possuem maior destaque no momento, além das propostas de criação desses institutos e depois apenas apresenta o seu resultado final, como, por exemplo, as de inauguração de escolas. As mensagens, entretanto, apresentavam relatos de como se encontrava a administração do Estado da Paraíba, tendo como público não a população em geral, mas o presidente e as demais autoridades das quais dependiam a liberação de recursos para a construção dessas obras, de forma que apresentavam, não raras vezes, os estágios em que se encontravam as obras públicas em geral e, particularmente, das instituições escolares.

Recebido em fevereiro-14

Aprovado em março-14 